\title{
Exploration and Practice of Improving the Quality of Graduate's Degree Awarding under the New Normal
}

\author{
Bo $\mathrm{Li}^{1, \mathrm{a}}$ \\ ${ }^{1}$ Jilin Agricultural University, Graduate School, Changchun130118, China \\ a 83574736@qq.com
}

Keywords: new normal, degree awarding, quality assurance system

\begin{abstract}
In recent years, the Chinese academic degree and graduate students education has made considerable development, but due to the complex students, diversified value orientation, the dramatic change of employment salutation caused the quality of graduate degree awarded is on a downward trend, how to ensure that the scale and quality of the synchronous development, is a new topic for graduate educators.
\end{abstract}

\section{Introduction}

Postgraduate education is a kind of education which is a kind of education of high level talents training after undergraduate course. It shoulders the important task of training high end talents for national modernization, and belongs to the highest stage of higher education. The degree awarding is the lifeline of graduate education, which is an important symbol of the two centers of teaching and scientific research in Colleges and universities. Therefore, more and more attention has been paid to the world, China as a big country of education, the degree and graduate education in the increasingly important position. Vice Premier Li Lanqing had stressed pointed out: "degree granting quality is not only related to the quality of the training of high-level personnel in our country, also have a direct impact on the reputation of our country".

In recent years, the Chinese academic degrees and graduate students education has made considerable development, enrollment continues to expand the scale, degree type increases day by day, training model is becoming more diverse, but due to the complex students, diversified value orientation, the employment situation is drastically change factors caused degree awarded the quality is on a downward trend, exactly how to resolve the "import" and "export" of the contradiction, and ensure the simultaneous development of scale and quality, is pendulum educators face a new topic in the research.

\section{The Problem and Cause Analysis of Graduate Education}

Decline in the Quality of Students. Due to the change of social environment and demand in enter oneself for an examination graduate number straight rise, from 1999 undergraduate enrollment policy since the implementation, it is not difficult to find a significant decline in quality of students after the expansion of enrollment, Graduate Enrollment undergraduate enrollment as a continuation of, will lead to a decline in the quality of students.

Selection of the students has been the implementation of the mechanism of the combination of the national college entrance examinations and school autonomy retest to ensure the graduate enrollment and quality of basic conditions, but in the actual admission process too much emphasis on test the ability of candidates, the proportion of the preliminary test result is too large. In addition, the results of the school from the proposition of professional courses to make it uniform line standards are not comparable, some colleges and universities to compete for students, to reduce the professional class papers standard, can not objectively reflect the overall quality of the candidates.

Single Training Mode. Compared with the developed countries diversified mode of education, education of high level talents in China's basic research is the training mode, training plan for academic theory, talent oriented, curriculum learning and academic training programs, emphasis on theoretical education, ignore the ability training, mainly reflected in: the curriculum emphasizes the 
standard form. Ignore the characteristics of mining resources; the content is old, far behind the latest academic progress; the teaching method is single, still by instilling the main teaching mode, is not conducive to the cultivation of students' innovation and practical ability, the cultivation of practical talents is relatively weak, can not meet the actual demand of talents in various industries.

Academic Environment Deterioration. Most colleges and universities on students in reading published academic papers, and use it as a degree granting the important basis. It can not only improve the graduate student's scientific research ability and academic level, and can make the academic degree evaluation awarded academic objective criteria, to improve the quality of degree thesis, is worth promoting. But part of the students under the pressure of school policy, afraid that you won't accomplish hard targets, could not successfully get the degree certificate, hesitate in academic activities make deviant behavior: plagiarize others' academic achievements; please ghostwriting thesis; tampering, forgery of data; a manuscript, etc., these behavior has been prevalent in colleges and universities, and even worse, serious pollution and health academic environment, influence degree granted by the quality.

Lack of Elimination Mechanism. Current research student training mode, the lack of proper competition and elimination mechanism, and most of the students think just admitted to the graduate, would be tantamount to into the "safe", "just come in, you have to go to the argument of" let the so-called "guarantee education quality, invisible to become an empty word and zero out the cultivation mechanism of growth students dawdle idea, lazy, lack of pressure and mission sense, the long-term trend continues, will lead to the decline of the quality of training graduate.

Education Resources are not Matching. Graduate education funds investment and advanced hardware facilities is to train postgraduate material base of high quality, improvement of the matching of the update of the introduction of teaching equipment, laboratory construction, experimental equipment, books and reference materials, the network resources of improvement, accommodation conditions are far behind in the current scale of education, not adapt to the development of graduate education.

\section{Exploration and Practice of Improving the Quality of Graduate Degree Granting}

Timely Decentralization, Strict Quality of the Source of Students. The quality of students is the basis and prerequisite for the formation and improvement of the quality of graduate education. If the cultivation of graduate students is compared to the production process of educational products, the entrance examination is the process of selecting raw materials. One is to optimize the test. Countries should as soon as possible to promote all types of graduate classification test, improve the selection and quality of region identification degree, to establish a scientific and reasonable selection standard, it is necessary to fully reflect the students' comprehensive professional quality, but also embody the selection examination "threshold" of the role in equity. Two is to strengthen the re. Local colleges and universities must pay full attention to the re examination of the "selection" effect and strengthen the retest of standardized and institutionalized construction, in addition to strictly in accordance with the student preliminary test and retest results should follow the principle of "three stick", adhere to the system of norms and the tutor responsibilities of both, adhere to equal emphasis on comprehensive quality and knowledge examination, adhere to equal emphasis on professional foundation and innovation ability, and effectively increase the retest of weight.

Classified Culture, Good Quality of the Training. Colleges and universities should carry out classified cultivation, teaching students according to their aptitude "principle, distinguish between different types of research orientation and training objectives, in view of the different type of degree, the establishment of scientific and rational classification training standards and degree granting standards.

Deepening the Reform of Training Mode. One is effectively change the graduate teaching way to enter the stage of postgraduate study, students have the basic knowledge of related disciplines and strong self-learning ability. Therefore, part of the course should not again to instill the way to teach, but should strengthen students' autonomous and inquiry of learning, strengthening case teaching, teaching of debate, Academic Salon and various academic lectures teaching mode, 
give full play to graduate to the subjective initiative of learning, cultivate the sense of innovation. Two is to actively improve the teaching content, to strengthen the systematic, cutting-edge and research content, focus on high-tech knowledge and traditional discipline knowledge system of grafting, closely follow the development of the discipline of professional fields.

Pay Close Attention to Links, Improve the Quality of the Degree Awarded off. Strengthen and regulate the thesis proposal, mid-term examination, to apply for a degree, the detection, the blind trial and graduation reply culture aspects of supervision and management, the establishment of elimination mechanism, in the training process does not meet the academic requirements of students, and resolutely implement to postpone graduation or be eliminated, to ensure the quality of products.

\section{Strengthen the Construction of the Tutor Team}

Improve the quality of postgraduate training depends on what? Strictly speaking, outstanding students just decided to raise the quality of secondary factors, tutor's role in the whole process management is the most direct factor, the improvement of knowledge structure and improve the academic level of students plays a vital role. With the current student scale rapid expansion, the proportion of tutor and postgraduate has serious imbalance: the star teacher up to a year to recruit 40-50 graduate students, these well-known mentor busy all day scientific or other everyday things, are simply too busy to take into account the guiding students, on the use of "put sheep style" management, or let the students act as its scientific labor; and part of the young teacher because of its "fame" for several years also fails to recruit a graduate student or even cancelled the qualification of teacher, which is difficult to ensure graduate education quality and education resources.

Clarity of Responsibilities. We should first make clear the tutor of graduate cultivation quality directly responsible. Secondly, teacher should more enjoy enrollment rights, distribution rights, the right to financial aid, the right to review and other rights, especially does not meet the academic requirements of the graduate student and supervisor shall have the right to termination instruction or ordered to drop out of the.

Establish and Perfect the System of Tutor Selection, Training and Assessment. One is the selection system. Guide the selection of teachers should be strictly from the scientific research level and the quality of the two aspects of the comprehensive assessment of the students, completely change not only the mentor for life; two is the training system. Schools should pay more attention to the regular training of instructors, especially the new selection of young instructors, strengthen support for them to participate in a variety of academic exchanges, and constantly improve the quality of teachers and academic level of the instructor team. Three is the assessment system. All colleges and universities should fully understand the importance of regular assessment of the business level of instructors, the establishment of evaluation system, the introduction of competition and elimination, reward and punishment, so as to ensure the quality of the tutor team of high quality, high level, high quality.

\section{Construction of Quality Assurance Aystem}

Building Information Network Management Platform. With the rapid development of modern network technology, the information network management of graduate education has become more and more prominent. At present our introduction and development of students education management system has been basically covered the from admission to student management, tutor management the training aspects of the operation and degree conferment of the whole process, for the majority of teachers and students build more convenient and efficient service platform, for scientific research, teaching and management to provide effective protection.

The Establishment of Postgraduate Training Two-Level Management System.Our school to promote the "graduate two-level management model" has been gradually realized the downward movement of the focus of the work culture, give full play to the College of graduate cultivation, dominant position of outstanding college management, strengthen process management and objective management, "school school subject" management platform, network system construction, 
do layers of regulation, layer upon layer is responsible for, school and college level to catch condominium together working pattern formation established a highly efficient and stable of graduate education management team.

Improve the Degree Awarding Mechanism. A further optimization of the academic degree committee management function and goal, grasp the key good policies and principles, at the same time to fully mobilize the initiative of the committee, expand the management autonomy, and play a sub committee in degree granting work in an important role. Two is the implementation of the graduate student's thesis supervisor responsibility system and quality responsibility system. Set up quality control system, effective use of "the blind trial", and "thesis detection system" way to encourage teachers to participate in the whole process management of dissertation, so as to promote the scientific and standardization, while continuing to improve the outstanding dissertation reward and incentive mechanism, to create an atmosphere of academic.

\section{Conclusion}

In the face of the " The 13th Five-year Plan" graduate education development and challenge, degree granting quality will cause greater attention, its quality is good or bad directly determine we transfer to the community what kind of "product", development shoulder heavy responsibilities, which requires every research student educators coagulation poly strength, continue to explore and forge ahead, and strive to create a new situation in the postgraduate education quality improved steadily.

\section{Reference}

[1] Shao Songhe. The status quo and Countermeasures of the training quality of master's degree students [D]. master's degree thesis of Wuhan University of Technology, 2008,04.

[2] Li Hongmei. Study on the quality control strategy of University Master's degree thesis [D]. master's degree thesis of Southwestern University, 2008,4.

[3] Wei Canxin. The quality of the status quo of China's education master's degree thesis and Countermeasure Study on the promotion of [J]. Northeast Normal University, 2009,05.

[4] Zhao Dan. Study on the evaluation of the quality of graduate students in Universities in Heilongjiang province [J]. Harbin Engineering University, 2009,4.

[5] Lu Bin. The study of flexible educational system for China's graduate education. The thesis of master's degree thesis of Chongqing University, 2007,4.

[6] Wu Sufang. Study on the training mode of master's degree of our country [D].Master Thesis of Jiangxi Normal University, 2007,4.

[7] Dong Ting. Research on the quality evaluation of graduate education.Wuhan University of Technology 2005.5

[8] Ma Dengxiu, Tao Yuan Lu. High graduate degree awarded the thinking and practice of quality [J]. China University of Petroleum, 2009.5

[9] Wang Yajie, Wang Peimin. The quality of Graduate Education: the macro level and the development strategy of [J]. higher education research, 2004

[10] Li Zhi. To strengthen the quality supervision and control to improve the quality of degree awarded [J]. graduate education, 2009 